NATHALIA CRUZ DE VICTO

\title{
IMPORTÂNCIA DE DICER NA PROGRESSÃO DO MELANOMA E NA RESISTÊNCIA AO TRATAMENTO QUIMIOTERÁPICO
}

Tese apresentada ao Programa de Pós-Graduação em Imunologia do Instituto de Ciências Biomédicas da Universidade de São Paulo, para obtenção do Título de Doutor em Ciências.

Área de concentração: Imunologia

Orientadora: Profa. Dra. Jacqueline de Fátima Jacysyn

Co-orientador: Prof. Dr. Niels Olsen Saraiva Câmara

Versão original 


\section{RESUMO}

Victo NC. Importância de Dicer na progressão do melanoma e na resistência ao tratamento quimioterápico. [Tese (Doutorado em Imunologia)]. São Paulo: Instituto de Ciências Biomédicas, Universidade de São Paulo, São Paulo; 2017.

O melanoma é um grave problema de saúde pública que afeta a população da América Latina e está aumentando rapidamente em comparação com outros tipos de tumores. Conhecer alguns marcadores moleculares de melanoma é essencial para a identificação de indivíduos geneticamente predispostos, bem como a detecção precoce da doença. Trabalhos recentes demonstraram que os microRNAs podem estar envolvidos na modulação do melanoma. Dicer é um membro essencial da família RNase III que controla a maturação de microRNA no citoplasma. Evidências recentes sugerem que a expressão de Dicer está envolvida no prognóstico de vários tipos de tumores. A up-regulação desta proteína está associada a características agressivas e proliferação de melanoma e nenhum outro tumor de pele. $O$ objetivo do nosso trabalho foi avaliar a expressão de Dicer em amostras de pacientes diagnosticados com melanoma nos diferentes estadios da doença e em linhagens celulares de melanoma correlacionando a expressão de Dicer com progressão tumoral e resistência à apoptose. Utilizando o ensaio de imuno-histoquímica, comparamos a proteína Dicer no tecido de pacientes diagnosticados com melanoma em diferentes estadios, os resultados sugerem que o aumento da expressão de Dicer está associado à progressão do melanoma. Para os ensaios in vitro, utilizamos a linhagem celular SK-MEL-5 e a ferramenta de edição do genoma CRISPR-Cas9 para o silenciamento de dicer1. Avaliamos nas linhagens transformadas a proliferação celular, capacidade clonogênica e sobrevida global. Nas condições testadas, a linhagem celular SK-MEL-5 DICER KD foi mais suscetível à apoptose após o tratamento com cisplatina. Essa sensibilidade pode ser pela regulação dos receptores de morte, FAS e TNFR1, expressados na linhagem SKMEL-5 DICER KD que estão envolvidos na indução de apoptose. Considerando os papéis biológicos fundamentais de Dicer em vários processos celulares concluímos que o aumento na expressão de Dicer está relacionado com a progressão do Melanoma e com a resistência ao tratamento com cisplatina.

Palavras-chave: Melanoma. Dicer. Apoptose. Cisplatina. 


\begin{abstract}
Victo NC. The importance of Dicer in the progression of melanoma and resistance to chemotherapy treatment. [Ph. D. thesis (Immunology)]. São Paulo: Instituto de Ciências Biomédicas, Universidade de São Paulo, São Paulo; 2017.

Melanoma is a serious public health problem that affects the population of Latin America and is rapidly increasing compared to other types of tumors. Knowing some molecular markers of melanoma are essential for the identification of genetically predisposed individuals, as well as the early diagnosis of the disease. Recent investigations have been demonstrated that microRNAs may be involved in melanoma modulation. Dicer is an essential member of the RNase III family that controls the maturation of microRNA in the cytoplasm. Recent evidence suggests that Dicer expression promotes prognosis of various types of tumors. Among all skin cancer up-regulation of Dicer is only associated with melanoma. The aim of this study was to evaluate the expression of Dicer in samples of patients diagnosed with melanoma at different stages of the disease and in melanoma cell lines correlating the expression of Dicer with tumor progression and resistance to apoptosis. Using the immunohistochemistry assay, we compared Dicer protein in the tissue of patients diagnosed with melanoma at different stages. We observed that the increased dicer expression is associated with melanoma progression. For the in vitro assays, we used the metastatic melanoma cell line, SK-MEL-5 and the CRISPR-Cas9 genome editing tool for dicer1 silencing. Cell proliferation, clonogenic capacity and overall survival were evaluated in the transformed cell lines. The SK-MEL-5 DICER KD cell line was more susceptible to apoptosis after treatment with cisplatin. We also found that the regulation of FAS and TNFR1 death receptors expressed by SK-MEL-5 DICER KD cell line potentially important in the induction of apoptosis. Considering the key biological roles of Dicer in various cellular processes, we conclude that the increase in Dicer expression is related to the progression of Melanoma and resistance to treatment with cisplatin.
\end{abstract}

Keywords: Melanoma. Dicer. Apoptosis. Cisplatin. 


\section{INTRODUÇÃO}

\subsection{Melanoma}

O câncer de pele do tipo melanoma é um problema grave de saúde pública que acomete a população da América Latina e vem aumentando rapidamente em comparação aos outros tipos de tumores (Schmerling et al., 2011). No Brasil, os tumores de pele são os mais frequentes e representam cerca de $30 \%$ de todos os tumores malignos registrados no país o melanoma representa apenas $3 \%$ das neoplasias malignas da pele, apesar de ser o mais agressivo devido à sua alta possibilidade de causar metástases. A estimativa de novos casos para 2016 (figura 1) foi de 5.670 , sendo 3.000 homens e 2.670 mulheres (INSTITUTO NACIONAL DO CÂNCER (INCA), 2016).

O risco de desenvolver melanoma estão associados com algumas características tais como: descendência europeia, cabelos loiros e ruivos, tom de pele claro, olhos claros, presença de sardas e/ou nevos melanocíticos, e histórico familiar de melanoma maligno (Dennis et al., 2008). Outras variáveis de alto risco incluem histórico de queimaduras solares, elevado número de queimaduras ao longo da vida e exposição solar intermitente (Wu et al., 2015).

O melanoma afeta igualmente homens e mulheres principalmente na quarta década de vida e normalmente são localizados no tronco $(43,5 \%)$, seguido pelas extremidades (33,9\%), cabeça e pescoço $(10,7 \%)$ e região acral $(11,9 \%)$ (Kuphal, Bossenhoff, 2009). Tem origem nos melanócitos, cuja alteração genética pode permitir a sua proliferação contínua e evasão, resultando no desenvolvimento de melanomas (Walia et al., 2012). 


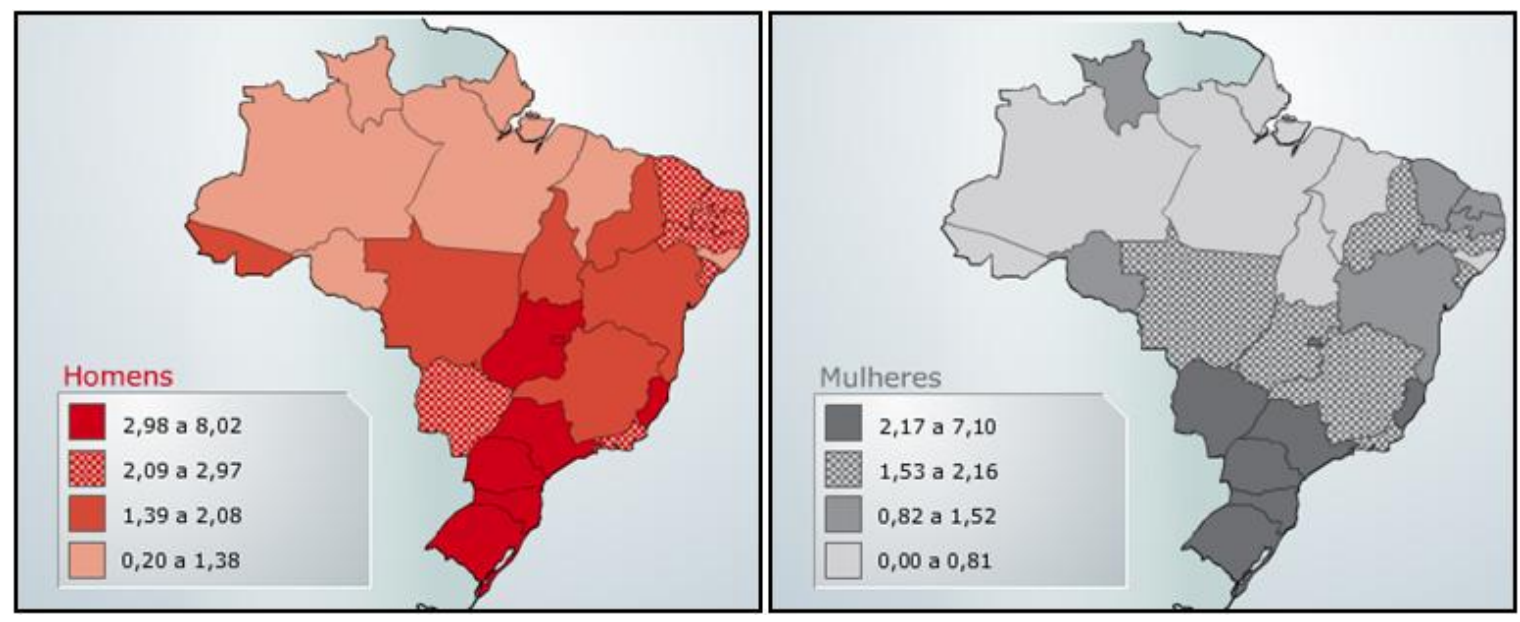

Figura 1 - Representação espacial das taxas brutas de incidência de melanoma por 100 mil habitantes. Vermelho para o sexo masculino e cinza para o sexo feminino, estimadas para o ano de 2016, segundo Unidade da Federação. Adaptado de INCA, 2016.

O melanoma pode surgir a partir de pele normal ou de uma lesão pigmentada. A manifestação da doença na pele normal se dá a partir do aparecimento de uma pinta escura de bordas irregulares podendo ser acompanhado de coceira e descamação. Quando a lesão é pré-existente, ocorre um aumento no tamanho, alteração da coloração e forma que passa a apresentar bordas irregulares (figura 2). Os tipos de lesão podem ser classificados como: superficial, mais comum em caucasianos (70\% dos casos); nodular, segunda maior frequência; lentigo maligno e acral lentiginoso, menos freqüente em caucasiano e comum entre indivíduos de pele escura. A coloração pode variar do castanho-claro chegando até a cor negra (melanoma típico) ou apresentar área com despigmentação (melanoma amelanócito) (Sharquie, et al., 2007; American Academy of Dermatology (AAD), 2013).

O tipo extensivo superficial corresponde a aproximadamente $70 \%$ dos casos, sua frequência é maior na região posterior das pernas de mulheres e no dorso dos homens (Newel et al., 1988). Esse tipo de tumor é normalmente encontrado em regiões expostas de pele, principalmente em regiões de exposição solar intermitente. Estendem-se além do componente dérmico, lateralmente por pelo menos três cones epiteliais; podendo surgir de novo ou em associação com um nevo (Clark et al., 1969; Crowson et al., 2001).

Melanomas nodulares ocorrem no tronco e membros de pacientes na quinta ou sexta décadas de vida (Barnhill, Mihm, 1993; Cox et al., 1996). Esse tipo de tumor não apresenta uma fase radial de crescimento que comprometa 
mais de três cones epiteliais, apenas uma fase vertical. Não são normalmente associados a regressão ou nevo (Clark et al., 1969; Crowson et al., 2001).

A $\quad$ B $\quad$ C $\quad$ D

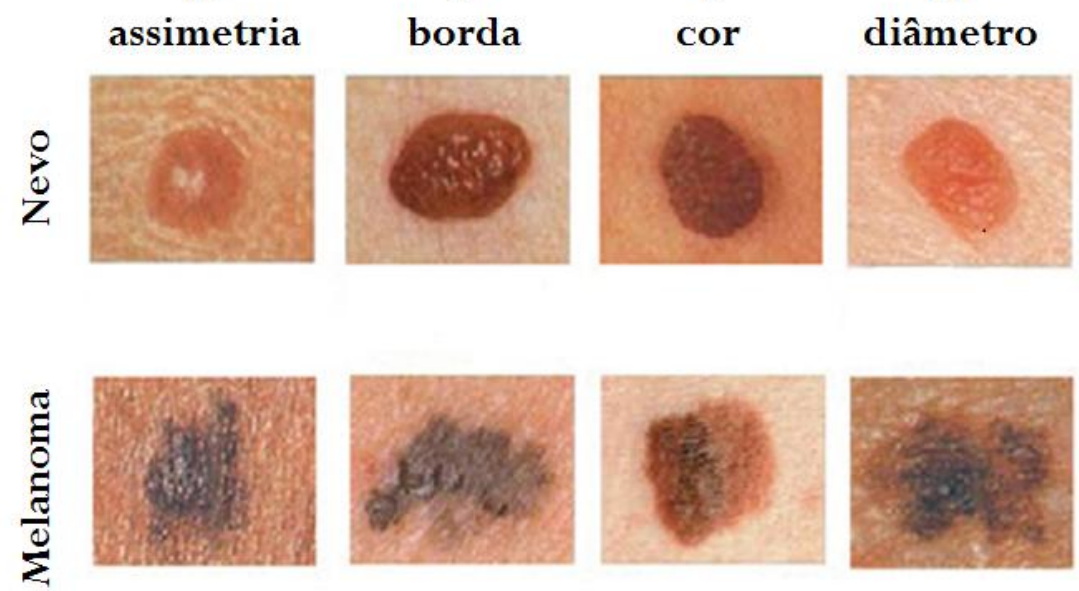

Figura 2 - Classificação ABCD para detecção do melanoma. A (assimetria); B (borda); C (cor) e D (diâmetro). Adaptado de Lupo Center for aesthetic \& general dermatology, 2016.

O tipo lentigo maligno está relacionado à exposição solar de longa data e idade avançada (Flotte, Mihm, 1999). Apresentam epiderme atrófica e são compostos por células melanocíticas atípicas, inicialmente isoladas e posteriormente em ninhos dispostos ao longo da junção dermo-epidérmica. Durante a progressão pode haver invasão de estruturas mais profundas. As células tumorais normalmente se estendem aos folículos pilosos e mostram intensa elastose solar na derme (Markovic et al., 2007).

Melanoma acral lentiginoso ocorre em pele glabra (que não possuem pelos) e adjacente dos dedos, palmas e plantas (Barnhill et al., 1993; Cascinelli et al., 1994). Melanomas digitais normalmente acometem o leito ungueal do hálux ou primeiro quirodáctilo e afetam pessoas mais idosas (O'Leary et al., 2000).

O crescimento ou alteração da forma do melanoma é progressivo e se faz no sentido horizontal e/ou vertical. $O$ índice de Breslow (estadiamento vertical) representa a espessura tumoral na derme em que, pacientes com lesões de espessura menor que $0,75 \mathrm{~mm}$ possuem prognóstico bom, ao contrário de lesões com espessura maior que $3 \mathrm{~mm}$ (Pinheiro et al., 2003). Este estadiamento é classificado em T (tumor primário): T0 (sem evidência de tumor primário); Tis (melanoma in situ); T1 (até $1 \mathrm{~mm}$ ); T2 (de 1,01 até $2 \mathrm{~mm}$ ); T3 (de 
2,01 até $4 \mathrm{~mm}$ ) e T4 (acima $4 \mathrm{~mm}$ ) (Balch et al., 2009). A classificação de Clark avalia o nível de invasão dividido em: I - crescimento intraepidérmico; II invasão da derme papilar; III - atinge o limite entre a derme papilar e reticular; IV - invasão da derme reticular e V - invasão da tela subcutânea (Gon et al., 2001).

Infelizmente, as lesões de melanoma podem permanecer imperceptíveis ou assintomáticas por longos períodos de tempo. Além disso, o melanoma pode se apresentar metastático no estadio IV, sem uma lesão claramente identificável, raramente restringe-se a focos únicos, mas tendem a se disseminar em vários órgãos que incluem cérebro e pulmões tornando as intervenções cirúrgicas limitadas (Melanoma Research Foundation, 2013).

A compreensão sobre a genética molecular que existe sobre o melanoma está se desenvolvendo gradativamente. Atualmente, tem-se o conhecimento de alguns genes envolvidos na sinalização intracelular responsáveis pela supressão tumoral, apoptose, crescimento e proliferação (Haluska et al., 2006). Uma importante via de sinalização alterada em pacientes com melanoma é a via RAS/RAF, em que a isoforma BRAF é alterada em $66 \%$ dos melanomas primários e em 40-68\% dos melanomas metastáticos. Esta ativação constitutiva contribui para a tumorigênese através do aumento da proliferação celular, invasão tumoral, metástase e de inibição de apoptose (Lopez-Bergami et al., 2008).

Outros marcadores moleculares também estão relacionados a fatores e/ou substâncias que podem identificar a presença ou a predisposição ao melanoma. Esses marcadores podem estar associados a alterações em determinadas regiões genômicas, como mutações em genes de predisposição (cdkn2a), como também estar relacionados à expressão de alguns antígenos em tumores e a presença de substâncias específicas na circulação sistêmica, podendo ser uteis para verificar o grau de desenvolvimento do melanoma assim como o seu prognóstico (Figueiredo et al., 2003). Como exemplos, esses marcadores dos melanócitos podem ser relacionados à diferenciação celular (tirosina, S100); relacionado a fatores de crescimento (VEGF e TGF- $\beta$ ); fatores de transcrição e moléculas de sinalização (PTEN e ATF-1); moléculas relacionadas a proliferação celular (Ki67, PCNA, Ciclinas); moléculas de adesão (E-caderina) e 
proteases (MMP-2, MMP-9) (Figueiredo, et al., 2003; de Wit, van Muijen, Ruiter, 2004).

$\mathrm{Na}$ tentativa de se encontrar marcadores moleculares, biomarcadores, para a detecção da progressão tumoral, os microRNAs vem se destacando por participarem da regulação de diferenciação, transdução de sinal, apoptose, proliferação e no processo de tumorigênese (Zoon, et al., 2009). A maioria dos alvos dos miRNAs são fatores transcricionais que por sua vez são cruciais para o crescimento e desenvolvimento celular.

\subsection{MicroRNA}

Os microRNAs (miRNAs) são uma família de RNAs endógenos, pequenos (de aproximadamente 19 a 25 nucleotídeos de comprimento), que não codificam proteínas e medeiam o silenciamento do gene postrancricional pela repressão de translação e clivagem do mRNA (Pan et al., 2013). Estudos mostraram que os miRNAs estão expressos em quase todos os eucariotos e estão envolvidos em uma variedade de processos biológicos, que incluem a regulação do ciclo celular, diferenciação, desenvolvimento, metabolismo e envelhecimento. Alterações na expressão dos miRNAs estão também envolvidas na iniciação, progressão e metástase em tumores (Calin et al., 2004; Lamy et al., 2006; Volinia, et al., 2010).

Os miRNAs podem controlar centenas de "genes alvo", o que ressalta o papel dessas moléculas sobre o perfil de expressão gênica e proteica nas células. Outros estudos mostraram que a presença de mutações em miRNAs estão correlacionadas ao desenvolvimento de neoplasias, indicando a possibilidade dessas moléculas atuarem como genes supressores de tumor ou como oncogenes (Kerscher, Slack, 2006; Rothschild, 2013). Alterações na expressão dos miRNA que conduzem ao desenvolvimento do tumor podem ocorrer através de alterações genéticas como: aberrações cromossômicas, mutações genéticas e polimorfismos dos genes miRNA e por alterações epigenéticas: alterações de metilação do DNA, acetilação ou alteração no rearranjo cromossômico (Gombos et al., 2013). 


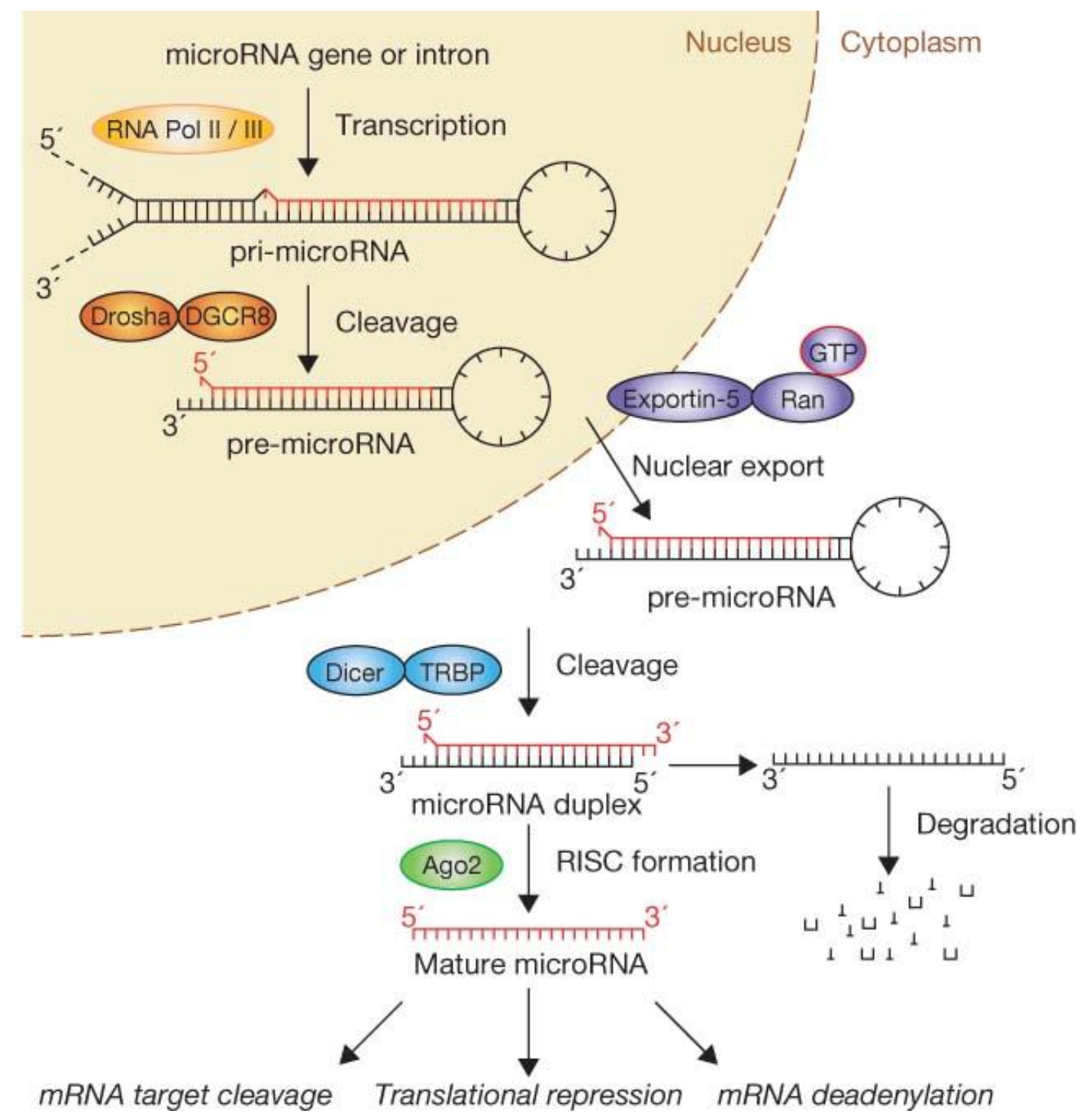

Figura 3 - Via de biogênese do microRNA. A enzima RNA polimerase II realiza a transcrição dos microRNAs primários (pri-miRNA). O complexo enzimático Drosha cliva os grampos formando precursores do miRNA (pre-miRNA), os quais são transportados para o citoplasma e associados ao complexo Exportin5-Ran-GTP-dependent (Exportin 5). No citoplasma, o pre-miRNA é clivado pelo complexo enzimático Dicer, perdendo a configuração em grampo. O miRNA fita-dupla formado associa-se à proteína Argonauta 2 e uma das fitas é acoplada ao complexo de proteínas que reprime a expressão do gene alvo (RISC), enquanto a outra é degradada. O RISC, contendo o microRNA, liga-se ao mRNA-alvo, reprimindo a sua tradução ou promovendo a sua degradação. Adaptado de Winter et al., 2009.

Os genes dos miRNAs (figura 3) são transcritos pela RNA polimerase II no núcleo a partir de uma região não codificadora ou não mensageira e formam o primeiro miRNA (pri-miR) (Unver et al., 2009). O pri-miR é processado também no núcleo, onde a RNAse II, Drosha, age sobre o pri-miR gerando o miRNA precursor (pre-miR), que é uma estrutura pequena de dupla fita de RNA com aproximadamente 65-70 nucleotídeos contendo um hair pin. O pre-miR é então exportados para o citoplasma por um complexo, exportin-5-RanGTP, e novamente processados por uma enzima RNAse III (Dicer) formando o miRNA 
maduro (fita dupla $m i R-m i R^{*}$, onde $m i R$ é o antisense, ou guia/vertente maduro, e $\mathrm{miR}^{*}$ é o sentido, ou vertente passageira) de aproximadamente 22 nucleotídeos (Gomes et al., 2013).

A estrutura do miRNA maduro é então incorporada em um complexo proteína/RNA denominado RISC (RNA-induced silencing complex), o qual é composto por Dicer, TRBP (HIV transactivating response RNA-binding protein) e Ago2 (Argonauta 2). O complexo miRNA/RISC liga-se ao mRNA de duas maneiras: o complexo miRNA/RISC liga-se fortemente com o mRNA quando as sequências seed são perfeitamente complementares, por intermédio da enzima Ago2, resultando na degradação do mRNA. Comumente, quando as sequências seed são imperfeitamente complementares, o complexo microRNA/RISC se liga e inibe a tradução do mRNA sem degradá-lo. O resultado final de qualquer uma destas vias é uma diminuição do nível de proteína do gene alvo (Zoon et al., 2009).

O lin-4 e o let-7, foram os primeiros miRNAs descritos no Caenorhabditis elegans (C. elegans) e participam de seu processo de desenvolvimento (Vella, Slack, 2005). Os miRNAs estão diferencialmente expressos nos diversos tecidos e a maioria apresenta padrões de expressão dependente do contexto celular, como observado em células hematopoiéticas e pancreáticas (Mattick et al., 2005). O desafio quando se trata de explorar as funções dos miRNAs é predizer seus potenciais alvos.

\subsubsection{Regulação de Dicer}

Dicer é um membro da família RNase III essencial que controla a maturação dos precursores de miRNAs (pré-miRNAs) no citoplasma (Bu et al., 2009). Em humanos, o gene dicer1 está localizado no cromossomo $14 q 32.13 \mathrm{e}$ possui 27 éxons (Ting et al., 2016). Além disso, a down-regulação de Dicer é detectável em $60 \%$ dos pacientes com câncer de ovário invasivo e está associado com pior diagnóstico (Kuang et al., 2013).

Está localizada no citoplasma, possui $200 \mathrm{kDa}$, sua estrutura tem a forma de um "L" e os domínios c-terminais de RNase III em tandem formando um dímero intramolecular para criar um centro catalítico (Foulkes, 2014). Os 
domínios RNase III de Dicer são essenciais para a maturação dos miRNAs. As mutações dentro dos domínios da RNase III-a e III-b modificam o processamento in vitro dos braços $3 p$ e $5 p$ do pré-miR, respectivamente. O domínio PAZ liga as extremidades livres do pré-miR e posiciona os domínios da RNase III para clivar o pré-miR a uma distância fixa a partir da extremidade 3p, no caso de Giardia, ou $5 p$, no caso de mamíferos, figura 4 (Gurtan et al., 2012).

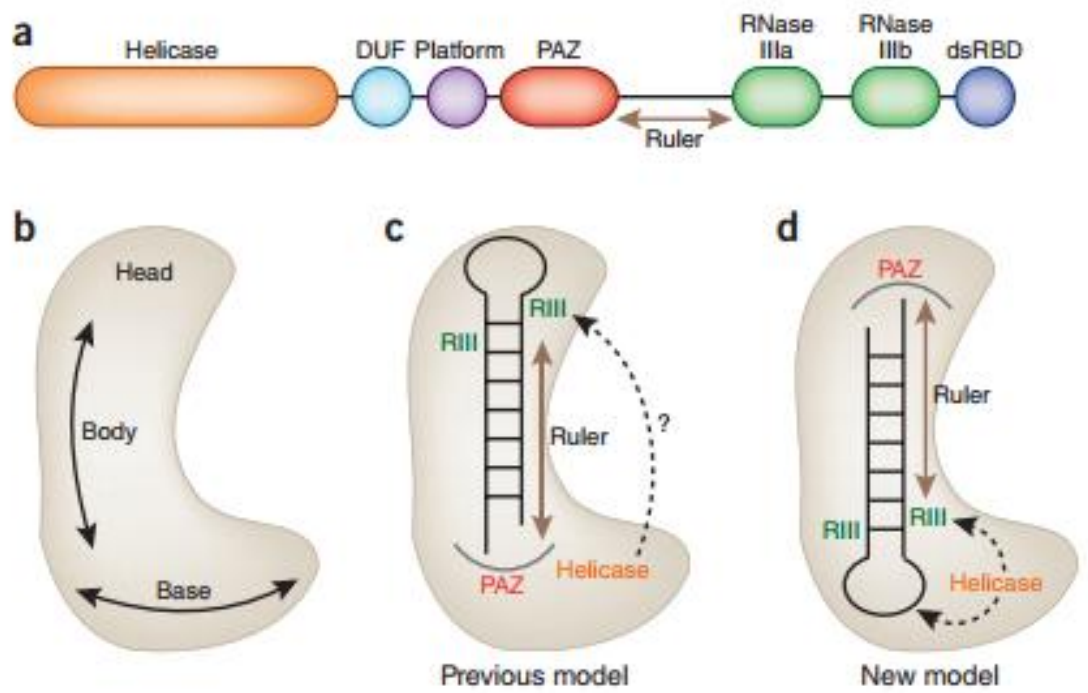

Figura 4 - Arquitetura de domínio Dicer Humano. (a) Estrutura esquemática do domínio de Dicer humano. (b) Desenho representativo da forma de Dicer humano de corpo inteiro com base em reconstrução EM. (c) Modelo anterior com a presença do Mirna ligado. (d) Novo modelo da arquitetura de Dicer com base em novos dados. Note-se a inversão de posições entre os domínios PAZ e RIll dentro da forma de $L$ com proximidade do domínio da helicase no hairpin do pré-miR e da RNase III (setas). Sawh, Duchaine, 2012.

Em mamíferos, Dicer forma um heterodímero transativado com a proteína TRBP, sendo que uma das funções desse conjunto é o reconhecimento e direcionamento dos distintos substratos da enzima até a integração com 0 complexo proteico silenciador da tradução (Macrae et al., 2006). Embora não seja necessário para a o processamento do pré-miR por Dicer, TRBP aumenta a fidelidade de clivagem e também preenche fisicamente Dicer com as proteínas Argonautas (Ago1, Ago2, Ago3 ou Ago4) para participar da montagem do complexo miRISC (Lin, Gregory, 2015).

A via convencional de biogênese dos miRNAs é a via canônica, ou, via dependente de Dicer (descrita anteriormente). A via não canônica foi descrita pela primeira vez durante a geração dos mirtrons, nessa etapa ocorre o escape do processamento mediado por Drosha e há a formação de um pequeno RNA resultante do splicing do mRNA. Depois da formação do splicing, o loop é 
desfeito e redobra em uma estrutura de stem-loop curta, que se assemelha a um pré-miR. Alguns mirtrons têm sequências extras no final 5'ou 3' e precisa ser cortado por exonucleases (Ha, Kim, 2014).

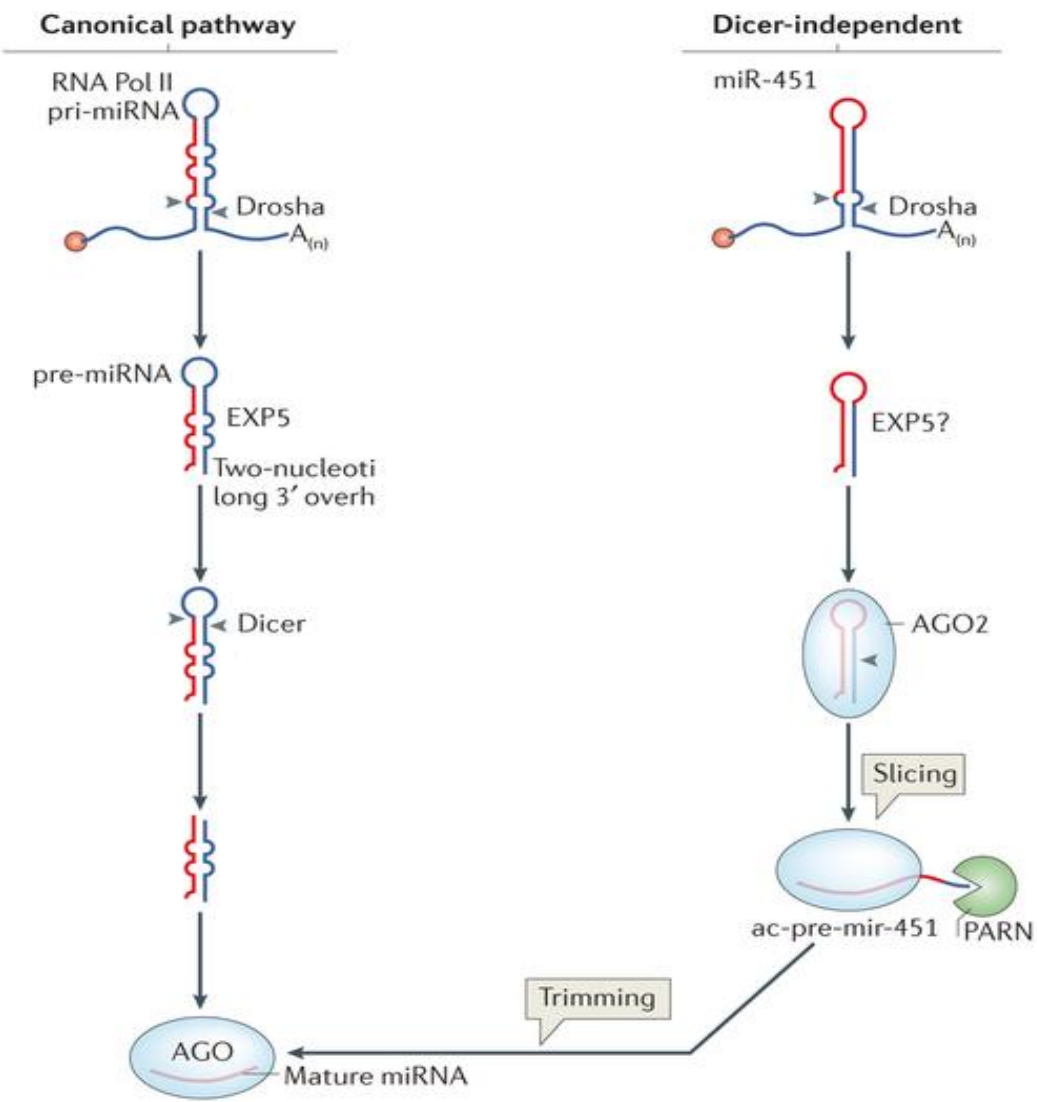

Figura 5 - Via canônica e Via independente de Dicer. Na via canônica de geração de miRNAs, os genes dos miRNAs são transcritos pelo complexo da RNA Pol II no núcleo. O processamento do pri-miR gerado é feito pela Drosha, uma proteína do tipo RNase III. O pré-miR gerado é então exportado para o citoplasma pela proteína Exportin-5, com o auxílio da proteína de transporte nuclear RAN-GTP. Uma vez no citoplasma, o pré-miR é convertido em duplex de miR através do complexo de Dicer dando continuidade para as etapas downstream da via. Alguns miRs podem ser gerados através de uma via independente de Dicer. Todas as etapas de transcrição e processamento do pri-miR ocorrem como descritas na via canônica. Ao chegar no citoplasma, no entanto, a proteína AGO2 em mamíferos é capaz de promover a maturação do pré-miR em Mirna, mesmo sem o auxílio de Dicer. Adaptado de Ha, Kim, 2014.

Embora a maioria dos precursores de miRNAs dependam de Dicer, a biogênese do miR-451, por exemplo, não necessita e envolve a atividade catalítica de Ago2 (figura 5). O rearranjo do miR-451 contém seis nucleotídeos terminais dos 23 de comprimento da sua região de extensão do loop e se estende para a cadeia complementar do precursor no hairpin (Cheloufi et al., 2010).

Alguns estudos avaliaram a expressão de Dicer na progressão do 
melanoma. Cheng e colaboradores, 2015, avaliaram seis biomarcadores de prognóstico independentes em melanoma, incluindo BRAF, MMP2, p27, Dicer, Fbw7 e Tip60, eles investigaram se estes marcadores são úteis na estratificação de risco dos pacientes com melanoma nos diferentes estadios. A expressão de Dicer apresentou uma redução sutil durante a progressão do melanoma (Cheng et al., 2015). Já Flavin e colaboradores forneceram evidências definitivas de que elF6 (eukaryotic translation initiation factor 6) e Dicer são regulados positivamente em uma proporção significativa no câncer de ovário e que ambos são associados com características clínico-patológicas específicas, mais notavelmente baixa expressão elF6 sendo associados à redução da sobrevivência (Flavin et al., 2008).

Embora as alterações no nível de expressão de Dicer, e possivelmente outras enzimas de processamento de miRNA, sejam de significado clínico em alguns tumores, estas alterações ou as suas consequências clínicas no melanoma ou outros tumores de pele permanecem desconhecidas.

Alguns grupos de pesquisa relacionam Dicer com a morte celular. Bian e colaboradores demonstraram que Dicer e Ago2 são fundamentais para os processos biológicos do câncer de próstata, pois atuam na proliferação, apoptose e ciclo celular, pois a redução na expressão de Dicer inibiu a proliferação celular e aumentou a apoptose em diferentes linhagens de câncer de próstata (Bian et al., 2014).

\subsection{Apoptose, Melanoma e Dicer}

A morte celular programada ou apoptose pode ser identificada por células com o DNA degradado, morfologia citoplasmática alterada, células que externalizam a fosfatidilserina ou que são ativadas por caspases (Festjens et al., 2006).

A via intrínseca de apoptose é ativada por estímulos intracelulares, como dano ao DNA, que gera a liberação do citocromo $c$ pela mitocôndria, essa liberação é regulada e dependente de duas proteínas da família BCL-2 (B-cell CLL/Lymphoma 2), BAX (BCL-2 associated X protein) e BAK (BCL-2 antagonist killer 1), que induzem alterações conformacionais na membrana mitocondrial. Animais e células knockout para essas duas proteínas são resistentes à morte induzida pela permeabilização mitocondrial que é induzida na presença de BAX e BAK. A liberação do citocromo c 
é um dos passos principais para a formação do apoptossomo. Uma vez liberado para o citosol, o citocromo $c$ se liga a APAF-1 (Apoptotic protease-activating factor 1) e na presença de um ATP recruta a caspase iniciadora, caspase-9, formando o apoptossomo e induz sua autoativação. A caspase- 9 torna-se ativa e em seguida ativa as caspases efetoras -3, - 6 e -7 desencadeando a apoptose (Du et al., 2000; Kemper et al., 2012; Zhao et al., 2012).

A via extrínseca é ativada através da ligação do receptor de morte da célula alvo ao seu ligante. Um dos receptores de morte mais conhecido é o FAS que se liga em seu ligante FASL. O sinal de ativação é transduzido através de domínios intracelulares (Chinnaiyan et al., 1995). FAS, também conhecido como CD95 ou APO-1, é um receptor de morte que regula a manutenção/homeostasia do sistema imune através da indução de apoptose (Chen et al., 2010). Outros receptores conhecidos são o DR4 (TRAIL-R1) e o DR5 (TRAIL-R2) que se ligam a TRAIL (tumor necrosis factor-related apoptosis inducing ligand). Os receptores de morte pertencem à superfamília dos receptores de TNF (tumor necrosis factor). A interação do receptor com seu ligante faz com que ocorra a sua oligomerização na membrana celular e iniciação da apoptose através do recrutamento de FADD (FAS-associated death domain) ou TRADD (TRAIL-associated death domain) que contém um DD (death domain) ligando ao DD do receptor. FADD então recruta através de seu DED (death effector domain) as caspases iniciadoras, caspase-8 ou -10 através do seu DED (Johnstone et al., 2008).

A formação desse complexo é designada DISC (death-inducing signaling complex). A ativação proteolítica das caspses-8 ou -10 no complexo DISC faz com que essas caspases sejam liberadas desse complexo, ativando dessa forma as etapas downstream da apoptose. Em células designadas do tipo I caspases efetoras, como a caspase- 3 , são ativadas diretamente pela caspase- 8 de um modo eficiente $e$ suficiente para induzir a apoptose. Em células denominadas do tipo II apenas uma pequena quantidade de caspase-8 ativa é liberada do DISC. Nessas células, a apoptose é dependente da clivagem da proteína BID que é um membro da família BCL-2 (Adam-Klages et al., 2005). A clivagem de BID pela caspase-8 gera um fragmento pró-apoptótico denominado tBID (truncad BID), essa forma truncada de BID transloca-se para a mitocôndria onde induz a agregação das proteínas BAX e BAK resultando no aumento da permeabilidade mitocondrial e consequentemente na liberação do citocromo $\mathrm{c}$, formação do apoptossomo executor e ativação da 
caspase-9, que ativa as caspases efetoras -3, -6 e -7 levando a célula a apoptose (Pereira, Amarante-Mendes, 2011)

Alguns miRNAs estão envolvidos no processo de apoptose e são denominados apoptomirs, como por exemplo, os miRNAs envolvidos na via extrínseca de apoptose, miRNA-221 e miRNA-222, os quais demonstraram estar mais expressos em células resistentes ao TRAIL e, em contrapartida, menos expressos em células sensíveis ao TRAIL (Garofalo, 2008). Entretanto, miRNA-24a está envolvido com a modulação da via intrínseca da apoptose por atuar na expressão da caspase-9. Um estudo de Walker e Harland mostrou que a perda da função do miRNA-24a leva ao aumento dos níveis da proteína caspase-9 sem alterar os níveis de mRNA, concluindo que esse miRNA é um regulador essencial desta caspase (Walker, Harland, 2009).

Ambas as vias de indução de apoptose convergem para a ativação das caspases efetoras (caspases-3,-6 e -7) que são responsáveis por desencadear os eventos de morte celular. O miRNA let-7a modula a expressão de caspase-3, interferindo no processo de apoptose induzido por drogas (Tsang, Kwok, 2008). Além disso, o let-7a também modula a proliferação celular, o que normalmente está alterado em células tumorais (Ambros, 2004).

O melanoma por sua vez resulta de alterações em vias de sinalização que afetam e controlam o crescimento, metabolismo e capacidade de escapar da apoptose, e entre essas vias estão PTEN/Akt. Durante o desenvolvimento tumoral, mutações e deleções de PTEN podem ocorrer, inativando sua atividade enzimática levando ao aumento da proliferação e redução da morte celular (Lopez-Bergami, Fitchman, Ronai, 2008). Alguns miRNAs tem demonstrado estar associado com a regulação negativa de PTEN, como o miR-17-5p, miR-1930, miR-21, miR-221 e miR222. Estes miRNAs provavelmente contribuem para quimio- ou radiorresistência devido sua expressão estar alterada nos tumores (Lima et al., 2011).

Em modelo in vivo de melanoma murino que tem a característica de gerar metástase no pulmão, Yang e colaboradores mostraram uma relação entre o miR-21 e a capacidade de metástases, quando inocularam células B16F10 wild type nos camundongos verificaram que há formação de metástase no pulmão. Por outro lado, quando inoculadas células B16F10 com o miR-21 deletado eles relataram que as células migram entretanto, a metástase causada é menor. Implicando que o miR-21 
possui a propriedade de causar metástase sendo esses dados importantes no diagnóstico clínico (Yang et al., 2011).

Jiang e colaboradores mostraram que o miR-21 pode desempenhar papel crítico no desenvolvimento do melanoma através de um estudo em que compararam a expressão do miR-21 em pacientes diagnosticados com melanoma e verificaram que a super-expressão do miR-21 está relacionada com o estadio clínico avançado na classificação de Breslow. Eles também mostraram que quando o miR-21 é inibido em linhagens de melanoma, a apoptose é induzida pela inibição da Akt fosforilada o que leva o aumento dos níveis de BAX e a diminuição dos níveis de BCL-2 (Jiang et al., 2012).

Ainda no contexto de apoptose, o miR-34 foi identificado como um potencial regulador do gene p53, sua expressão ectópica pode induzir a parada do ciclo celular em G1, senescência e apoptose sugerindo que o miR-34 pode atuar como um supressor tumoral. A expressão alterada desse miRNA é encontrada durante a progressão do melanoma (Howell et al., 2010). Estes achados sugerem que a via da p53 exerce um importante papel na modulação da expressão desses miRNAs e na condução das células à morte, uma vez que p53 é uma proteína pró-apoptótica e pode ter sua expressão bastante alterada nos tumores (Raver-Shapira et al., 2007). O fato dos miR-34a, miR34b e miR-34c estarem diferencialmente expressos em tumores sólidos, desperta o interesse em desvendar seu papel em outras neoplasias e no controle da apoptose no melanoma.

As alterações que levam ao desenvolvimento do melanoma surgem através de eventos genéticos e epigenéticos. Os eventos epigenéticos alteram a expressão gênica sem afetar a sequência de nucleotídeos do DNA (Xing, 2007). Estes mecanismos incluem: modificações das histonas (ubiquitinação, fosforilação, ribosilação e acetilação), edição do RNA, silenciamento gênico por RNA não codificante (miRNAs e RNAs de interferência) e a metilação do DNA (Grunstein, 1997; Wade et al., 1999).

Novas estratégias para identificação de biomarcadores epigenéticos no melanoma podem auxiliar na conduta clínica. Há um aumento nas evidências de que o silenciamento epigenético de alguns miRNAs no melanoma possuem um papel importante. Entretanto, existem poucos dados sobre essa desregulação dos miRNAs no melanoma e seu envolvimento no desenvolvimento e progressão da doença (Sun et al., 2014). 
Gaur e colaboradores caracterizaram os níveis de expressão e a correlação biológica de 241 miRNAs maduros em 59 linhagens tumorais humanas que compõem o painel NCl-60 e identificaram 15 miRNAs que diferenciam o melanoma de outros tumores sólidos (Gaur et al., 2007). Enquanto isso, Nguyen e colaboradores analisaram amostras de pacientes com melanoma nos estadios I, II, III e IV, segundo a classificação AJCC (American Joint Committee on Cancer), e identificaram que a expressão do miR-29c está inversamente correlacionada com a expressão de DNMT3 (DNA metiltransferase), uma vez que, os estadios I e II apresentaram um aumento na expressão do miR-29c e uma diminuição de DNMT3 e os estádios III e IV essa relação foi inversa. O miR-29c é responsável por regular funções celulares que incluem ativação de genes supressores, inibição da metiltransferase e regulação de genes anti-apoptóticos (Nguyen et al., 2011).

Estudos demonstram que a up-regulação de Dicer está associada com características de agressividade e proliferação do melanoma (melanócitos) e não de outros tumores de pele (Ma et al., 2011). Jafarnejad e colaboradores analisaram a expressão nuclear de Dicer em tecidos de pacientes diagnosticado com melanoma nos diferentes estádios segundo a classificação AJCC e identificaram uma correlação entre a expressão nuclear de Dicer com o prognóstico desses pacientes. Os resultados obtidos no estudo sugerem que há uma redução na expressão de Dicer nuclear durante a progressão do melanoma (Jafarnejad et al., 2012).

Considerando as funções biológicas de Dicer em vários processos celulares e a sua regulação em diferentes tipos de tumores, pode-se inferir que a modulação de Dicer é um candidato promissor para diagnóstico. 


\section{CONCLUSÃO}

Concluimos que o aumento na expressão de Dicer está relacionado com a progressão do Melanoma e com a resistência ao tratamento com cisplatina.

A linhagem SK-MEL-5 DICER KD apresentou ser mais sensível à indução de apoptose após tratamento. Esta sensibilidade ocorreu, nas condições testadas, pela regulação dos receptores de morte FAS e TNFR1 que estão expressos nessa linhagem e possuem um impacto na morte induzida por apoptose. 


\section{REFERÊNCIAS*}

Adam-Klages $S$, Adam D, Janssen $O$, et al. Death receptors and caspases: role in lymphocyte proliferation, cell death, and autoimmunity. Immunol Res. 2005;33(2):149-66.

Al-Badr AA, Alodhaib MM. Dacarbazine. Profiles Drug Subst Excip Relat Methodol. 2016;41:323-77.

Algazi AP,Soon CW, Daud Al. Treatment of cutaneous melanoma: current approaches and future prospects. Cancer Manag Res. 2010; 2: 197-211.

Amarante-Mendes GP, Griffith TS. Therapeutic applications of TRAIL receptor agonists in cancer and beyond. Pharmacology \& Therapeutics. 2015;155:117-31.

Ambros V. The functions of animal microRNAs. Nature. 2004;431:350-5.

American Academy of Dermatology (AAD). [cited from 13 out. 2013]. Disponível em: http://www.skincarephysicians.com/skincancernet/four_types.html

Armstrong BK, Kricker A. Cutaneous Melanoma. Cancer Surv. 1994;19-20:219-40.

Balch CM, Gershenwald JE, Soong S, et al. Final Version of 2009 AJCC Melanoma Staging and Classification. Journal of Clinical Oncology. 2009:27(36):6199-6206.

Barnhill RL, Mihm MC. The histopathology of cutaneous malignant melanoma. Semin Diagn Pathol. 1993;10:47-75.

Basu A, Krishnamurthy S. Cellular responses to Cisplatin-induced DNA damage. J Nucleic Acids 2010;pii: 201367:1-16.

Bian XJ, Zhang GM, Gu CY, et al. Down-regulation of Dicer and Ago2 is associated with cell proliferation and apoptosis in prostate cancer. Tumor Biol. 2014;35:11571-8.

Bragança AC, Volpini RA, Mehrotra $P$, et al. Vitamin D deficiency contributes to vascular damage in sustained ischemic acute kidney injury. Physiological Reports. 2016;4(13):e12829.

Bu Y, Lu C, Bian C, et al. Knockdown of Dicer in MCF-7 human breast carcinoma cells results in G1 arrest and increased sensitivity to cisplatin. Oncology Reports. 2009;21:13-7.

Calabresi P, Welch AD. Chemotherapy of neoplastic diseases. Annu. Rev. Med. 1962;13:147-202.

Calin GA, Liu CG, Sevignani C, et al. MicroRNA profiling reveals distinct signatures in $B$ cell chronic lymphocytic leukemias. Proc. Natl. Acad. Sci. U.S.A. 2004;101:11755-60.

${ }^{*}$ De acordo com: International Committee of Medical Journal Editors. [Internet]. Uniform requirements for manuscripts submitted to Biomedical Journal: sample references. [updated 2011 Jul 15]. Available from: http://www.icmje.org 
Cascinelli N, Zurrida S, Galimberti V, et al. Acral lentiginous melanoma: a histhological type without prognostic significance. J Dermatol Surg Oncol. 1994;20:817-22.

Cheloufi S, Dos Santos CO, Chong MMW, et al. A Dicer-independent miRNA biogenesis pathway that requires Ago catalysis. Nature. 2010;465(3):584-90.

Chen L, Park SM, Tumanov AV, et al. CD95 promotes tumour growth. Nature. 2010;465(7297):492-6.

Cheng Y, Lu J, Chen G, et al. Stage-specific pprognostic biomarkers in melanoma. Oncotarget. 2015;6(6):4180-9.

Chinnaiyan AM, O'Rourke $\mathrm{K}$, Tewari $\mathrm{M}$, et al. FADD, a novel death domaincontaining protein, interacts with the death domain of Fas and initiates apoptosis. Cell. 1995;81(4):505-12.

Clark WH, From L, Bernardino EA, et al. The histogenesis and biologic behavior of primary human malignant melanomas of the skin. Cancer Res. 1969;29:705-27.

Cong L, Ran FA, Cox D, et al. Multiplex genome engineering using CRISPR/Cas systems. Science. 2013;339(6121):819-23

Cox NH, Aitchison TC, Sirel JM, et al. Comparison between lentigo maligna melanoma and other histogenetic types of malignant melanoma of the head and neck. Br J Cancer. 1996;73:940-4.

Crowson NA, Magro CM, Mihm MC. The melanocytic proliferations: a comprehensive textbook of pigmented lesions. New York: Wiley-Liss. 2001;p539.

Cullen SP, Martin SJ. Fas and TRAIL 'death receptors' as initiators of inflammation: Implications for câncer. Seminars in Cell \& Developmental Biology. 2015;39:26-34.

Dennis LK, Vanbeek MJ, Beane Freeman LE, et al. Sunburns and risk of cutaneous melanoma: does age matter? A comprehensive meta-analysis. Ann Epidemiol. 2008 Aug;18(8):614-27.

de Wit $\mathrm{NJ}^{1}$, van Muijen GN, Ruiter DJ. Immunohistochemistry in melanocytic proliferative lesions. Histopathology. 2004 Jun;44(6):517-41.

Dimatos DC, Duarte FO, Machado RS, et al. Melanoma Cutâneo no Brasil. Arquivos Catarinenses de Medicina. 2009;38:14-9.

Du C, Fang M, Li Y, et al. Smac, a mitochondrial protein that promotes cytochrome c-dependent caspase activation by eliminating IAP inhibition. Cell. 2000;102(1):33-42.

Fennell DA, Summers Y, Cadranel J, et al. Cisplatin in the modern era: The backbone of first-line chemotherapy for non-small cell lung cancer. Cancer Treatment Reviews. 2016;44:42-50. 
Festjens N, Cornelis S, Lamkanfi M, et al. Caspase-containing complexes in the regulation of cell death and inflammation. Biol Chem. 2006;387(8):1005-16.

Figueiredo LC, Cordeiro LN, Arruda AP, et al. Câncer de pele:estudo dos principais marcadores moleculares do melanoma cutâneo. Ver Brasileira de Cancerologia. 2003;49(3):179-83.

Flavin RJ, Smyth PC, Finn SP, et al. Altered elF6 and Dicer expression is associated with clinicopathological features in ovarian serous carcinoma patients. Modern Pathology. 2008;21:676-84.

Flotte TJ, Mihm MC. Lentigo maligna and malignant melanoma in situ, lentigo maligna type. Hum Pathol. 1999;30:533-6.

Foulkes WD, Priest JR, Duchaine TF. DICER1: mutations, microRNAs and mechanisms. Nature Reviews Cancer. 2014:1-11.

Franken NAP, Rodermond HM, Stap J, et al. Clonogenic assay of cells in vitro. Nature Protocols. 2006;1(5):2315-19.

Galluzzi L, Senovilla L, Vitale I, et al. Molecular mechanisms of cisplatin resistance. Oncogene. 2012;31(15):1869-83.

Garbe C, Eigentler TK, Keilholz U, et al. Systematic review of medical treatment in melanoma: current status and future prospects. Oncologist. 2011;16(1):5-24.

Garofalo M, Quintavalle C, Di Leva G, et al. MicroRNA signatures of TRAIL resistance in human non-small cell lung cancer. Oncogene. 2008;27: 3845-55.

Gaur A, Jewell DA, Liang Y, et al. Characterization of microRNA expression levels and their biological correlates in human cancer cell lines. Cancer Research. 2007;67:2456-68.

Genome-scale CRISPR Knock-Out (GeCKO). [cited from 06 nov. 2016]. Disponível em: http://genome-engineering.org/gecko/wpcontent/uploads/2013/12/lentiCRISPRv2-and-lentiGuide-oligo-cloning-protocol.pdf

Gershenwald JE, Thompson W, Mansfield PF, et al. Multi intitucional melanoma lymphatic mapping experience: the prognostica value of sentinel lymph node status in 612 stage I or ii melanoma patients. J Clin Oncol. 1999;17:976-83.

Ghavami S, Hashemi M, Ande SR, et al. Apoptosis and cancer: mutations within caspase genes. J Med Genet 2009;46:497-510.

Gombos K, Horvath R, Szele E, et al. miRNA Expression Profiles of Oral Squamous Cell Carcinomas. Anticancer Research. 2013;33:1511-18. 
Gomes AQ, Nolasco S, Soares H. Non-Coding RNAs: Multi-Tasking Molecules in the Cell. Int. J. Mol. Sc. 2013;14:16010-39.

Gon AS, Minelli L, Guembarovski al. Melanoma cutâneo primário em Londrina. An Bras Dermatol. 2001;76(4):413-26.

Grunstein M. Histone acetylation in chromatin structure and transcription. Nature. 1997;389:349-52.

Gurtan AM, Lu V, Bhutkar A, et al. In vivo structure-function analysis of human Dicer reveals directional processing of precursor miRNAs. RNA. 2012;18:1116-22.

Ha M, Kim VN. Regulation of microRNA biogenesis. Molecular Cell Biology. 2014;15:509-24.

Haluska FG, Tsao H, Wu H, et al. Genetic Alterations in Signaling Pathways in Melanoma. Clin Cancer Res. 2006;12(7 Suppl):2301s-07s.

Hammond SM. Dicing and slicing: the core machinery of the RNA interference pathway. FEBS Lett. 2005;579:5822-9.

Hanahan D, Weinberg RA. Hallmarks of cancer: the next generation. Cell. $2011 ; 144(5): 646-74$.

Hoffend N, Magner WJ, Tomasi TB. The modulation of Dicer regulates tumor immunogenicity in melanoma. Oncotarget. 2016;7(30):47663-73.

Howell PM, Li X, Riker Al, et al. MicroRNA in melanoma. The Ochsner Journal. 2010;10(2):83-92.

Instituto Nacional do Câncer (INCA). [cited from 15 jun. 2016]. Disponível em: http://www2.inca.gov.br/wps/wcm/connect/tiposdecancer/site/home/pele_melanoma

Ivanov VN, Bhoumik A, Ronai Z. Death receptors and melanoma resistance to apoptosis. Oncogene. 2003;22:3152-61.

Jafarnejad SM, Sjoestroem C, Ardekani GS, et al. Reduced expression of nuclear Dicer correlates with melanoma progression. Pigment Cell Melanoma Res. 2012;26:147-9.

Jiang L, Lv X, Li J, et al. The status of microRNA-21 expression and its clinical significance in human cutaneous malignant melanoma. Acta Histochemica. 2012;114:582-8.

Jemal A, Siegel R, Ward E, et al. Cancer Estatistics, 2008. CA Cancer J Clin. 2008;58(2):71-96.

Jinek $M$, Chylinski K, Fonfara I, et al. A programmable dual-RNA-guided DNA endonuclease in adaptive bacterial immunity. Science. 2012 Aug 17;337(6096):81621 
Johnstone RW, Frew AJ, Smyth MJ. The TRAIL apoptotic pathway in cancer onset, progression and therapy. Nat Rev Cancer. 2008;8(10):782-98.

Kalady MF, White RP, Johnson JL, et al. Thin melanomas:predictive lethal characteristics from a 30-year clinical experience. Ann Surg. 2003;238:528-37.

Kamei T, Inui M, Nakamura S, et al. Interferon- - and anti-Fas antibody-induced apoptosis in human melanoma cell lines and its relationship to bcl-2 cleavage and bak expression. Melanoma Research. 2003;13:153-9.

Kemper K, Rodermond H, Colak S, et al. Targeting colorectal cancer stem cells with inducible caspase-9. Apoptosis. 2012;17(5):528-37.

Kerscher A, Slack FJ. Oncomirs, microRNAs with a role in cancer. Nature. 2006;6:259-69.

Khan N, Lawlor KE, Murphy JM, et al. More to life than death: molecular determinants of necroptotic and non-necroptotic RIP3 kinase signaling. Current Opinion in Immunology. 2014;26:76-89.

Khoshnaw SM, Rakha EA, Abdel-Fatah TM, et al. Loss of Dicer expression is associated with breast cancer progression and recurrence. Breast Cancer Res Treat. 2012;135:403-13.

Koberle B, Tomicic MT, Usanova S, et al. Cisplatin resistance: preclinical findings and clinical implications. Biochim Biophys Acta. 2010;1806(2):172-82.

Kotowski U, Heiduschka G, Brunner M, et al. Arsenic trioxide enhances the cytotoxic effect of cisplatin in head and neck squamous cell carcinoma cell lines. Oncol Lett. 2012;3(6):1326-30.

Kuang Y, Cai J, Li D, et al. Repression of Dicer is associated with invasive phenotype and chemoresistance in ovarian câncer. Oncology Letters. 2013;5: 1149-54.

Kumar MS, Pester RE, Chen CY, et al. Dicer1 functions as a haploinsufficient tumor suppressor. GENES \& DEVELOPMENT. 2009;23:2700-4.

Kuphal S, Bosserhoff A. Recent progress in understanding the pathology of malignant melanoma. J Pathol. 2009;219(4):400-9.

Lamy $\mathrm{P}$, Andersen $\mathrm{CL}$, Dyrskjot $\mathrm{L}$, et al. Are microRNAs located in genomic regions associated with cancer? Br. J. Cancer. 2006;95:1415-8.

Leemans $\mathrm{CR}$, Braakhuis BJ, Brakenhoff $\mathrm{RH}$, et al. The molecular biology of head and neck cancer. Nat Rev Cancer. 2011;11(1):9-22.

Lens MB, Eisen TG. Systemic chemotherapy in the treatment of malignant melanoma. Expert Opin Pharmacother.2003;4(12):2205-11. 
Lima RT, Busacca S, Almeida GM, et al. MicroRNA regulation of core apoptosis pathways in cancer. Europen Journal of Cancer. 2011;47:163-74.

Lin S, Gregory RI. MicroRNA biogenesis pathways in cancer. Nature Reviews Cancer. 2015;15:321-33.

Linos E, Swetter SM, Cockburn MG, et al. Increasing burden of melanoma in the United States. J Invest Dermatol. 2009;129(7):1666-74.

Lopez-Brgami P, Fitchman B, Ronai Z. Understanding signaling cascades in Melanoma. Photochemistry and Photobiology. 2008;84:289-306.

Lupo Center for aesthetic \& general dermatology [cited from 20 july 2016]. Disponível em: http://www.drmarylupo.com/skin-cancers/index.html

Ma Z, Swede H, Cassarino D, et al. Up-regulated Dicer expression in patients with cutaneous melanoma. PlosOne. 2011;6(6):e20494.

Macrae IJ, Zhou K, Repic A, et al. Structural basis for double-stranded RNA processing by Dicer. Science. 2006;311(5758):195-8.

Mandalà M, Massi D. Tissue prognostic biomarker in primary cutaneous melanoma. Virchows Arch. 2013:1-17.

Mattick JS, Makunin IV. Small regulatory RNAs in mammals. Hum. Mol. Genet. 2005;14:121-32.

Markovic SN, Erickson LA, Rao RD, et al. Malignant melanoma in the $21^{\text {st }}$ century, Part I: Epidemiology, risk factors, screening, prevention and diagnosis. Mayo Clin Proc. 2007;82:364-80.

Melanoma Research Foundation. [cited from 13 out. 2013]. Disponível em:

http://www.melanoma.org/understand-melanoma/what-is-melanoma/metastaticmelanoma

Merritt WM, Bar-Eli M, et al. The Dicey Role of Dicer: Implication for RNAi Therapy. Cancer Res. 2010;70(7):2571-4.

Middleton MR, Grob JJ, Aaronson N, et al. Randomized phase III study of temozolomide versus dacarbazine in the treatment of patients with advanced metastatic malignant melanoma. $\mathrm{J}$ Clin Oncol. 2000 Jan;18(1):158-66.

Ministério da Saúde. [cited from 21 mar. 2014]. Disponível em: http://bvsms.saude.gov.br/bvs/saudelegis/sas/2013/prt0357_08_04_2013.html

Nalejska E, Maczynska E, Lewandowska MA. Prognostic and Predictive Biomarkers: Tools in Personalized Oncology. Mol Diagn Ther. 2013:1-12. 
Newell GR, Sider JG, Bergfelt L, et al. Incidence of cutaneous melanoma in the United States by histology with special reference to the face. Cancer Res. 1988;48:5036-41.

Nguyen T, Kuo C, Nicholl MB, et al. Downregulation of microRNA-29c is associated with hypermethylation of tumor-related genes and disease outcome in cutaneous melanoma. Epigenetics. 2011;6(3):388-94.

O'Leary JA, Berend KR, Johnson JL, et al. Subungual melanoma: a review of 93 cases, with identification of prognostic variables. Clin Orthop Relat Res. 2000;378:206-12.

Pan X, Wang R, Wang Z. The potential role of miR-451 in cancer diagnosis, prognosis, and therapy. Mol Cancer Ther. 2013;12(7):1-10.

Pereira WO, Amarante-Mendes GP. Apoptosis: a programme of cell death or cell disposal?. Scand J Immunol. 2011;73(5):401-7.

Pinheiro AMC, Friedman H, Cabral AL, et al. Melanoma cutâneo: características clínicas, epidemiológicas e histopatológicas no hospital universitário de Brasília entre janeiro de 1994 e abril de 1999. An Bras Dermatol. 2003;78(2):179-86.

Pouliot LM, Shen DW, Suzuki T, et al. Contributions of microRNA dysregulation to cisplatin resistance in adenocarcinoma cells. Exp Cell Res. 2012 Feb 15;319(4):56674.

Raver-Shapira N, Marciano E, Meiri E, et al. Transcriptional activation of miR-34a contributes to p53-mediated apoptosis. Mol. Cell. 2007;26:731-43.

Redondo $\mathrm{P}$, Solano $\mathrm{T}, \mathrm{Va}^{\prime}$ zquez $\mathrm{B}$, et al. Fas and Fas ligand: expression and soluble circulating levels in cutaneous malignant melanoma. British Journal of Dermatology. 2002;147:80-6.

Rodriguez W , Jin L, Janssens V, et al. Deletion of the RNaselll Enzyme Dicer in Thyroid Follicular Cells Causes Hypothyroidism with Signs of Neoplastic Alterations. PLoS ONE. 2012;7(1): e29929.

Rothschild SI. Epigenetic therapy in lung cancer - role of microRNAs. Frontiers in oncology. 2013;158(3):1-5.

Sand M, Gambichler T, Sand D, et al. Immunohistochemical expression patterns of the microRNA-processing enzyme Dicer in cutaneous malignant melanomas, benign melanocytic nevi and dysplastic melanocytic nevi. Eur J Dermatol. 2011;21:18-21.

Sawh AN, Duchaine TF. Turning Dicer on its head. Nat Struct Mol Biol. 2012 Apr 4;19(4):365-6

Scanlon CS, Van Tubergen EA, Inglehart RC, et al. Biomarkers of epithelialmesenchymal transition in squamous cell carcinoma. J Dent Res. 2013;92(2):114-21. 
Swahari V, Nakamura A, Deshmukh M. The paradox of dicer in câncer. Molecular \& Cellular Oncology. 2016;3(3):e1155006.

Schadendorf D, Fisher DE, Garbe C, et al. Melanoma. Nature Reviews Disease Primers. 2015;1:1-20.

Schmerling RA, Loria D, Cinat G, et al. Cutaneous melanoma in Latin America: the need for more data. Rev Panam Salud Publica. 2011;30(5):431-8.

Serrone L, Zeuli M, Sega FM, Cognetti F. Dacarbazine-based chemotherapy for metastatic melanoma: thirty-year experience overview. J Exp Clin Cancer Res. 2000 Mar;19(1):21-34.

Sharquie KE, Al-Meshhadani SA, Al-Nuaimy AA. Acral lentiginous melanoma versus Ientigo maligna melanoma among Iraqi patients. Saudi Med J. 2007;28(1):105-7.

Siddik ZH. Cisplatin: mode of cytotoxic action and molecular basis of resistance. Oncogene. 2003;22(47):7265-79.

Strillacci A, Griffoni C, Lazzarini G, et al. Selective cyclooxygenase-2 silencing mediated by engineered $\mathrm{E}$. coli and RNA interference induces anti-tumor effects in human colon cancer cells. Br J Cancer. 2010;103(7):975-86.

Su Z, Yang Z, Xu Y, et al. Apoptosis, autophagy, necroptosis, and cancer metastasis. Molecular Cancer. 2015;14(48):1-14.

Sun V, Zhou WB, Majid S, et al. MicroRNA-mediated regulation of melanoma. British Journal of Dermatology. 2014;171:234-41.

Swahari V, Nakamura A, Baran-Gale J, et al. Essential Function of Dicer in Resolving DNA Damage in the Rapidly Dividing Cells of the Developing and Malignant Cerebellum. Cell Rep. 2016;14(2):216-24.

Tang K, Ren H. The Role of Dicer in DNA Damage Repair. Int. J. Mol. Sci. 2012;13(12):16769-78.

Ting TW, Brett MS, Cham BWM, et al. DICER1 deletion and 14q32 microdeletion syndrome: an additional case and a review of the literature. Clinical Dysmorphology. 2016;25:37-40.

Tsang WP, Kwok TT. Let-7a microRNA suppresses therapeutics-induced cancer cell death by targeting caspase-3. Apoptosis. 2008;13:1215-22.

Unver T, Namuth-Covert DM, Budak $\mathrm{H}$. Review of CurrentMethodological Approaches for characterizing MicroRNAs in Plants. International Journal of Plant Genomics. 2009; Article ID 262463, 11 pages.

Vella MC, Slack FJ. C. elegans microRNAs. WormBook. 2005;21:1-9. 
Venza M, Visalli M, Catalano T, et al. Impact of DNA methyltransferases on the epigenetic regulation of tumor necrosis factor-related apoptosis-inducing ligand (TRAIL) receptor expression in malignant melanoma. Biochem. Biophys. Res. Commun. 2013;441:743-50.

Volinia S, Galasso M, Costinean S, et al. Reprogramming of miRNA networks in cancer and leukemia. Genome Research. 2010; 20:589-99.

Wade PA, Geggone A, Jones PL, et al. Mi-2 complex couples DNA methylation to chromatin remodeling and histone deacetylation. Nat Genet. 1999;23:62-6.

Walker JC, Harland RM. microRNA-24a is required to repress apoptosis in the developing neural retina. Genes Dev. 2009;23:1046-51.

Walia V, Mu EW, Lin JC, et al. Delving into somatic variation in sporadic melanoma. Pigment Cell Melanoma Res. 2012;25:155-70.

Winter J, Jung S, Keller S, et al. Many roads to maturity: microRNA biogenesis pathways and their regulation. Nature Cell Biology. 2009;11:228-34.

Wu CF, Wang HM, Huang WK, et al. Efficacy and safety of bio-chemotherapy with dacarbazine plus interleukin-2 in patients with unresectable malignant melanoma. Asia Pac J Clin Oncol. 2015;11(4):314-8.

Xing M. Gene methylation in thyroid tumorigeneses. Endocrinology. 2007;148(3):948-53.

Yang $\mathrm{CH}$, Yue J, Pfeffer SR, et al. MicroRNA miR-21 regulates the metastatic behavior of B16 melanoma cells. The Journal of Biological Chemistry. $2011 ; 286(45): 39172-8$.

Zaidi MR, Merlino G. The Two Faces of Interferon-y in câncer. Clin Cancer Res. 2011;17(19): 6118-24.

Zhao L, He F, Liu H, et al. Natural diterpenoid compound elevates expression of Bim protein, which interacts with antiapoptotic protein $\mathrm{Bcl}-2$, converting it to proapoptotic Bax-like molecule. J Biol Chem. 2012;287(2):1054-65.

Zoon CK, Starker EQ, Wilson AM, et al. Current molecular diagnostics of breast cancer and the potential incorporation of microRNA. Expert Rev Mol Diagn. 2009; $9(5): 455-67$. 